\title{
Engaging Linguistically Diverse Populations: Gatekeepers in Rural and Sparsely Populated Areas of the U.S. Midwest
}

Denice Adkins, University of Missouri

Heather Moulaison Sandy, University of Missouri

\begin{abstract}
In the Midwestern U.S., there is a growing population of Latin American immigrants. This increase is driven largely by employment opportunities in generally low-skilled, low wage fields such as meat processing and packing, and other agricultural fields. As a result, rural towns with relatively few resources are welcoming a growing number of non-English speaking immigrants who may not have experience with the practices and institutions of the U.S. such as libraries, schools, hospitals, or social support services. The agencies that usually work with linguistically diverse immigrant populations are churches, schools, and university extension departments. Building off previous research, this paper reports on ten interviews with gatekeepers about their work in reaching and engaging with Latin American immigrant populations. Three interrelated themes emerged from the interviews: the importance of language, of providing relevant services, and of cultivating trust. Drawing from the experiences reported by the gatekeepers as well as the literature, the authors discuss implications for small rural libraries that might not be equipped to take over gatekeeping roles, but that want to work with immigrant communities. Ultimately, the authors recommend that rural libraries liaise with established gatekeepers to the greatest extent possible.
\end{abstract}

Keywords: gatekeepers; immigrants; Latin American immigrants; Midwestern U.S.; rural and sparsely populated areas

Publication Type: research article

\section{Introduction}

$\mathrm{T}$ here is a growing population of Latin American immigrants living and working in the Midwestern United States (U.S.), especially in rural and sparsely-populated areas (Jensen, 2006; Kandel \& Newman, 2004; Lichter, 2012). Such communities in the Midwest are historically insular and largely without a tradition of hosting newcomers (see Kandel \& Newman, 2004; Lichter, 2012), yet they are seeing an influx of non-English speaking immigrants to the country who may not have experience with the culture and practices of the U.S. and/or with its institutions, such as libraries, schools, hospitals, or social support services. These host communities are "ill-prepared" (Jensen, 2006, p. 7) to receive the newcomers. As the U.S. Department of Agriculture's Economic Research Service noted in 2004 as part of its projections for the future, "many rural communities are unprepared for significant numbers of culturally different low-paid [Latin American immigrant] newcomers who seek inexpensive housing, require particular social services, and struggle to speak English" (Kandel \& Newman, 2004, para. 21). Although a number of research projects have focused on people with Latin American heritage in densely-populated urban areas (e.g., Krogstad \& Lopez, 2017), "[r]ural and small town America have been largely excluded from these discussions" (Lichter, 2012, p. 6). 
Yet, Latin American immigrants are increasingly moving to the Midwestern U.S., and the host communities find themselves needing to support them. The U.S. Census Bureau (2011) reported that the Hispanic ${ }^{1}$ population in the Midwest had increased by nearly 50 percent between 2000 and 2010. The increase in this population is driven largely by employment opportunities in relatively low-skilled, low wage positions, such as in meat processing and packing plants, and work in other parts of the agricultural sector (see Kandel \& Newman, 2004; "Latinos Surge in Midwest," 1996). These opportunities tend to cluster around employers' factories, which are often located in rural and low-population density areas. The full extent of the Latin American heritage population may potentially be unacknowledged due to irregular immigration statuses, with one estimate that "almost 25 percent of the workers in 222 meatpacking plants in Nebraska and lowa were illegally in the US" ("Latinos Surge in Midwest," 1996, para. 8). The Pew Research Center's Hispanic Trends (2016) estimates, for example, that in 2014, there were 55,000 unauthorized immigrants in Missouri, 75,000 in Kansas, and 450,000 in Illinois. The Pew Research Center's Hispanic Trends (Krogstad, Stepler, \& Lopez, 2015) indicates that since the 1980s, roughly only one-third of Spanish-speaking ${ }^{2}$ newcomers are proficient in English; the remaining two-thirds will require additional support in their native language to function effectively in society.

Since the number of Latin American immigrants is on the rise in the U.S. Midwest, and since some of them may not have documentation of their immigration status, or may have family members who are undocumented, there may be a distrust of governmental institutions that inhibits their interaction with these agencies (Adkins, Moulaison Sandy, \& Derpic, 2017). How, then, should cultural institutions, such as rural libraries, engage with linguistically diverse immigrant populations and represent their interests? And what might libraries in these areas stand to learn from the work that is already being done? The agencies that usually work with linguistically diverse immigrant populations are churches (e.g., Kim, 2016), schools (e.g., Blanchard \& Muller, 2015), and, in the case of the rural Midwest, university extension departments. ${ }^{3}$ The agencies and institutions that work with linguistically diverse immigrant populations in rural areas face a number of challenges: a lack of bilingual personnel, limited funds to hire personnel and/or purchase materials, and a reliance upon grant funds to develop projects (e.g., Adkins \& Hempel, 2016).

In this paper, the authors have two goals:

a) first, to introduce a study that represents agencies and institutions officially serving Latin American immigrants, as well as others who function as gatekeepers and work with the Latin American heritage population in rural and low-population areas of the Midwestern U.S.; and

b) second, to seek to apply that knowledge to the work that libraries and information agencies carry out in serving new immigrants in rural and low-population areas of the Midwest. In considering the ongoing effort and commitment required to engage immigrant communities, the authors of this study propose that information agencies, such as libraries, adopt certain strategies for providing services and resources to users of Latin American heritage. For example, if they are working with minimal resources, libraries could be more effective through establishing partnerships with gatekeepers rather than to trying to become gatekeepers themselves. 


\section{Literature Review}

\section{Who Are Gatekeepers?}

Gatekeepers are "information intermediaries who move between cultures" (Agada, 1999, p. 74). Past studies have shown that community gatekeepers, such as "law enforcement, Adult Protective Service[s], case managers, postal carriers, physicians, apartment managers, senior center staff, clergy, paramedics, code-enforcement personnel, and so forth" (Kim, 2016, p. 131), can be effective in getting services to difficult-to-serve populations. The concept of gatekeeping builds on Lewin's (1947) article discussing how information flows are affected by "gates," where gatekeeping agents make decisions to let information pass or not. White (1950) used this concept in the context of publishing, identifying editors as gatekeepers who decide which stories to publish, thereby framing social awareness of information. Barzilai-Nahon (2008) tied together the concept of gatekeeping with network theory, and while her focus was on technology, she also discussed the way the term "gatekeeper" had been used in a variety of contexts, including social and community-based contexts. One context for the use of the term is that adopted by library and information science (LIS) professionals and social workers, whereby the term "gatekeeper" refers to people who move between the insiders and outsiders of a cultural group, exchanging information and allowing researchers access to a particular community. In the context of gatekeepers working with Latin American immigrants in the Midwest, gatekeepers are necessarily bilingual and able to navigate successfully through both cultures: the Midwestern American host culture, which is more widely found in this region, and the newcomers' Latin American culture.

\section{Gatekeepers and Their Work with Underrepresented Populations}

Previous research on the roles of gatekeepers defines them as intermediaries moderating between the mainstream community and another community, such as the urban poor or ethnolinguistically marginalized communities (Agada, 1999). Chu (1999b) looked at information professionals as gatekeepers and the need for cultural relevance in communicating information with them. Chu (1999a) also did research on immigrant children serving as language brokers for their parents and others, as well as focusing on building culturally appropriate ways of bringing information to linguistic minority populations. In her work, Chu (1999a; 1999b) assumed that librarians themselves would take on the role of gatekeeper(s), and points out, for instance, that newcomers who work may not have time or transportation to attend literacy classes, and that literacy work should start in the newcomer's first language and remain as culturally relevant as possible.

Outside of the LIS literature, there is also interest in gatekeepers and their roles, especially since gatekeepers use a variety of strategies to engage with linguistically diverse communities. The use of newcomers' native language is key to communicating information (Trudell, 2012). Most gatekeepers are bilingual and bicultural, as linguistic and cultural skills are needed to share information effectively. Further, it is difficult for host community members to reach members of the newcomer community without a gatekeeper to first establish trust (Edwards, 2013, p. 509). In the context of social work, social workers [gatekeepers] influence who gets access to the newcomer community (Bucerius, 2013, p. 702), and what information is provided to the community. The literature on gatekeepers notes the critical and defining role that gatekeepers have in allowing access to and sharing information with a community of interest, much as Metoyer-Duran (1991) noted that some gatekeepers worked to preserve the heritage culture and discourage assimilation into the larger culture. 


\section{Gatekeepers and Information Flow}

Metoyer-Duran (1991) studied gatekeepers who provided information to ethnically and linguistically diverse populations, and identified several types of gatekeepers in her work: the Impeder who guards against sharing too much information, the Broker who facilitates information sharing, the Unaffiliated gatekeeper who does not represent a particular institution, the Affiliated gatekeeper who has a formal relationship with a non-library institution, the Information Professional whose job is to provide information, and the Leader/Executive who is in a highly visible role.

Gatekeepers choose when and how they pass information; they also choose what information to share and they designate the recipients. Kim (2016) investigated Korean church pastors' willingness to share information about specific Medicare programs and the 211 non-emergency information and referral line. ${ }^{4}$ Many of the churches (43\%) already provided some social services to their congregations, including medical services, but Kim reported that outreach sessions were hard to schedule unless a church had already been providing this service (p. 138). The pastors were more aware of some unmet needs than the researchers were (p. 135). Teachers can also function as gatekeepers. Blanchard and Muller (2015), investigating the role of teachers as gatekeepers for non-English speaking immigrant children, found that teachers are more likely to perceive immigrant students as hard-working but also as less likely to complete college. These beliefs may be likely to shape children's perspectives of themselves, which may influence children's likelihood to pursue more demanding college preparatory classes. As a result, their “perceptions may reproduce inequality through gatekeeping” (Blanchard \& Muller, 2015, p. 273).

Gatekeepers also decide when and how outsiders or members of the host community gain access to community members. Some gatekeepers may be less willing to expose their communities to outsiders, either because they fear that outsiders will take advantage of their community members without providing adequate benefit or because they fear that community members might harm the outsider. This latter example was the case in one article, where a gatekeeper was reluctant to provide access to a community of young immigrant men who had a history of drug dealing (Bucerius, 2013).

Each of the authors cited here presents gatekeepers as culture-crossers, people who work within two (or more) cultures to share information. However, each of these authors also presents gatekeeping as primarily a one-way street: that the information from the host culture flows to and is used by newcomers to improve their lives.

\section{Midwestern Interview Locations}

From late 2016 through the summer of 2017, researchers interviewed ten individuals who are considered gatekeepers (see Appendix A for information about the location and the characteristics of the gatekeepers). Interviews took place in the Midwestern U.S., a relatively rural and agriculture-based area of the country. Rural areas of the Midwest have traditionally been white and English-language monolingual, although they have a long history of German and Scandinavian immigration (Lichter, 2012), and many of the previous generations in these areas were German speakers. ${ }^{5}$ Some Latin American immigrants had come to urban areas in the Midwest as early as the late $19^{\text {th }} /$ early $20^{\text {th }}$ centuries, forming small communities that have adapted to living amid the Midwestern host culture, so larger Midwestern cities often have more integrated communities of Latin American immigrants and their descendants (Martinez, 2011). By and large, however, researchers visited smaller communities ill-equipped to work with new immigrants. The arrival of Latin American immigrants to communities not prepared to welcome them presents an interesting opportunity for study (Kandel \& Newman, 2004), since these areas 
generally have not experienced large influxes of new populations for several generations, producing culture shock in both the newcomer populations and the receiving communities. In response to the "browning" ("Latinos Surge in Midwest," 1996, para. 2) of the U.S. Midwest, a term used to describe the growth of the Latin American heritage population, the UC Davis Rural Migration News notes that "[g]iven their small populations, rural towns can be transformed almost overnight by immigration, leading to issues that range from an inability to communicate with public authorities to non-English speaking children in school" ("Latinos Surge in Midwest," 1996, para. 3). Smaller host communities, such as the ones visited as part of this research, can therefore quickly find themselves burdened by the arrival of the newcomers, unfamiliar with their needs and unprepared to welcome them.

Indeed, not all members of the receiving community welcome the newcomers. "Newcomers speaking a different language, eating different foods, attending different churches, and rearing children differently can spark fear, hostility, and indignation in rural populations that have remained stable for generations" (Jensen, 2006, p. 8). Given the potential for hostility and a lack of appreciation in these communities, the reasons newcomers choose to immigrate might not be immediately obvious. The answer, however, lies largely in employment opportunities in these areas. Employment opportunities are generally available in relatively low-skilled, low wage sectors (see Kandel \& Newman, 2004; "Latinos Surge in Midwest," 1996), and recruitment for this work helped result in Latin American heritage populations accounting "for more than one-quarter of the total population growth in rural areas" (Jensen, 2006, p. 12). These openings are often located in smaller towns which may use incentives such as "low or no taxes, free land, 'spec' buildings, and other incentives” (Stull \& Broadway, 2013, p. 221).

Anecdotally, there is also a sense that the values of rural host communities in the Midwest align well with the family-oriented culture of newly arrived Latin American immigrants. In his study of rural immigration patterns based on census data, Jensen (2006) states in the executive summary "At the risk of romanticizing, the image of these new arrivals is of a group of people in rural areas who are striving to live up to American values of hard work, marriage, homeownership, and making a contribution" (p. 7). Jensen goes on to note in the body of the report, "The immigrants, largely Hispanic, appear to be drawn to employment opportunities first and foremost, but also to the lower costs of housing, good schools, and an environment that is regarded as safe and peaceful" (Jensen, 2006, p. 27). The basic values of both communities seem to be in concert, even if the current political situation is creating additional challenges for newcomers (see Adkins, Moulaison Sandy, \& Derpic, 2017).

\section{Engaging Immigrant Community Members}

Engagement with the host community by new immigrants supports integration. Kogan (2006) posits that when immigrants are incorporated into their new communities politically and socially, through activities like being welcomed, attending community meetings, and participating in cultural education provided by the government, they are more likely to integrate into their new communities by becoming citizens. Immigrants who arrive in their new location as children adapt more quickly, likely due to their engagement in the school system (Rumbaut, 2004). Some immigrants are more engaged in cultural organizations to build bridges between the immigrant and receiving communities, and to build new social networks (Jensen, 2008).

Engagement, therefore, is a key component that drives immigrants' integration into their new countries or regions of settlement, as indicated by Berry and Hou (2016). In many cases, gatekeepers are the intermediaries who encourage newcomer populations to engage with local efforts such as participation in health classes provided by university extension departments. The

The International Journal of Information, Diversity, \& Inclusion, 2(1-2), 2018

ISSN 2574-3430, publish.lib.umd.edu/IJIDI/ 
messages transmitted at such events may blend across cultures - encouraging mothers to look at providing healthy food for their families, while at the same time advocating against traditional high-fat or high-sugar foods. Enticing newcomers to engage in these kinds of programs requires a skillful gatekeeper who can help make sense of the cross-cultural messages while still motivating people to participate.

\section{Information Needs of New Immigrants}

The information needs of the Latin American heritage community and the information needs of new immigrants have been reviewed at length. Ayala and Ayala (1994), Haro (1970), and LuevanoMolina (2001) have all reported on the needs of library users with Latin American heritage, who sought Spanish-language materials, Spanish-speaking staff, and more culturally-relevant materials such as videos and music from their public libraries. As early as 1990, Cuesta clarified that the needs of an established Latin American heritage community would be different from the needs of new immigrants, with new immigrants needing more daily survival information and established communities needing more cultural support. Caidi, Allard, and Quirke (2010) identified several information needs of immigrants, including information on language, employment, community connections, housing, health, workplace safety, legal information, and information about education, recreation, transportation, and banking (pp. 504-505). Speaking of "service needs," Kim discussed access to information about benefits, such as home help and financial assistance, health information, and services offered by outside agencies, all of which were impeded by the language barrier (Kim, 2016, p. 139).

Previous research has been conducted on researchers' perceptions of the needs of Latin American immigrants and Latin American heritage populations in the Midwest. Adkins and Hempel (2016) did a content analysis of conference abstracts submitted to the Cambio de Colores (Change of Colors) conference (http://www.cambiodecolores.org/), an annual, regional conference focusing on the changing demographics of the Midwestern U.S. and the integration of Latin American heritage newcomers. Cambio de Colores conference presenters include researchers, university extension personnel, and social services agents. After analyzing 402 conference abstracts submitted between 2005 and 2014, Adkins and Hempel (2016) identified several perceived information needs, including health-related information, financial knowledge, knowledge of jobs and employment, and knowledge of educational resources. Language was identified as a major barrier to information communication. Not presenting knowledge in a culturally appropriate way was identified as a barrier, though this was seen as a lesser barrier than the language difference. Adkins and Hempel (2016) also noted as potentially problematic that the information needs that were identified might have been influenced by grant funders' priorities.

\section{Language and New Immigrants}

Language and the culture it supports can present barriers for new immigrants who are otherwise linguistically and culturally isolated from members of the language-majority culture and therefore unable to engage. Technology such as translation apps can provide verbatim translations, but meanings and cultural significance may nonetheless be lost. Recognizing the words and understanding their intended meaning, implications, and connotations may not go hand in hand for newly arrived immigrants (e.g., Shiu-Thornton, Balabis, Senturia, Tamayo, \& Oberle, 2007).

Kim (2016) identifies language as a primary barrier for Korean immigrants, particularly older Korean immigrants who may experience social isolation. While this barrier was partially ameliorated by Korean church pastors who worked with the populations, the pastors who were

The International Journal of Information, Diversity, \& Inclusion, 2(1-2), 2018

ISSN 2574-3430, publish.lib.umd.edu/IJIDI/ 
interviewed felt the language barrier created a gap between the information Korean seniors needed and the information they could get. Other barriers included the Korean seniors' lack of familiarity with the types of social and medical services offered in the U.S. compared to Korea, and the cultural values of the U.S.

In their work promoting linguistically and culturally relevant medical information as a way of engaging newcomers, Shirazi, Shirazi, and Bloom (2015) found that work with Afghan women involved more than simple translations, but rather a broad and deep understanding of their culture. In particular, they found that

the development and planning of [our program] involves much more than just a Farsi/Dari translation of materials and messages. Rather, it consists of collective strategies, culturally tailored for appropriateness and competency. The program recognizes the importance of faith and spirituality in this community and, by incorporating Islamic components that are important and inspirational to the lives of participants, it reframes Islam as a facilitator of women's health. (p. 158)

This deep understanding allowed them to integrate messages about women's health in a way that all members of the community, i.e., both women and their male relatives, would understand and internalize.

\section{Method and Research Questions}

\section{Rationale for the Study}

This research topic came out of a larger project involving Latin American heritage communities in the Midwestern U.S. The larger project focused on the use of information and communication technologies by Latin American immigrants and their descendants, along with their information needs and interests. The crucial role played by gatekeepers, both in connecting to their communities and in providing access to the communities for outsiders, became obvious through the course of that project, leading inductively to the exploratory research questions addressed below.

In the project presented in this article, the use of gatekeepers originated as a means to an end, but became an object of inquiry and investigation after reviewing their behaviors in context. The original research project was designed to use structured interviews with members of the Latin American heritage community. Interviews with gatekeepers were primarily to be used for confirmatory review, with reflections about gatekeepers' interviews restricted to field notes. After five interviews with gatekeepers had been collected and field notes discussed, the decision was made to expand the project to include an exploration of gatekeepers' roles in providing information and access to their communities. Because this idea emerged organically in the process of study, this research has developed to become phenomenological in nature although it was not conceived of as such from the start.

\section{Research Questions (RQs)}

The use of gatekeepers as key contacts to reach the desired informants (Midwestern Latin American heritage populations who used technologies) was originally intended. After several interviews, however, the role that gatekeepers were playing in moderating between researchers and the community of interest emerged as much more significant, which was summarized with the first RQ explored in this article: 
$\mathrm{RQ}$ 1: What is the role of gatekeepers to Latin American immigrant communities in rural and low-population areas of the U.S. Midwest?

Given that the study is conducted in the context of LIS, the authors also sought to understand how best to apply the findings to LIS professionals working with similar immigrant communities. Therefore, the second RQ emerged:

RQ2: What can library and information professionals learn from the work of gatekeepers in terms of better serving immigrant communities, especially in rural and low-population areas of the U.S. Midwest?

\section{Interview Methodology}

During this research project, the study's authors interviewed ten community gatekeepers from the communities of differing sizes, as listed in Appendix A. The gatekeepers were identified through the University of Missouri (MU)'s Cambio Center (http://www.cambio.missouri.edu/), an organization affiliated with the MU Extension (http://extension.missouri.edu/) program. The Cambio Center on the University of Missouri campus has a long history of working with Midwestern Latin American heritage populations, often in relation to large grants from the agricultural sector, and they put the authors in contact with several gatekeepers who could give them access to informants from the Latin American heritage communities.

The research design established for the overarching project required finding a number of gatekeepers, who would go on to set up anonymous interviews for the authors with informants from the Latin American community. Interviews were scheduled with these gatekeepers, primarily to understand their interpretations of their populations' social media and mobile technology use. Semi-structured interviews with gatekeepers focused on questions of information and access to information as well as strategies for working with members of the Latin American heritage community. A list of preliminary questions for gatekeepers can be found in Appendix B. The protocol was designed to focus on research questions about social media and mobile technologies; however, questions about community and interactions dominated the interview time with gatekeepers, and very little time was spent with questions about social media. Gatekeepers shared stories of their own perceptions and actions related to moderating between two communities, including what they saw, felt, and heard in various situations. This rich qualitative data provided by the gatekeepers allowed for insight into gatekeepers' lived experiences as gatekeepers, and served as a catalyst for further study focusing on the unique roles that gatekeepers play.

Gatekeepers explained how they worked with the linguistically diverse immigrant population, described the strategies they used to reach new community members, and, in some cases, also volunteered information about how they kept that community engaged. Engagement is a key component that drives immigrants' integration into their new countries or regions of settlement, as indicated by Berry and Hou (2016).

\section{Coding and Analysis}

Because the original project did not focus on gatekeepers, only five of the total ten gatekeeper interviews are transcribed. During initial gatekeeper interviews, notes were made on paper, but as the potential importance of the gatekeepers' information became apparent for areas beyond social media and mobile technologies, the decision was made to formally document and transcribe later gatekeeper interviews.

During the first five interviews, extensive notes were made at the time of the interview, documenting the information provided by the gatekeeper in that interview. The interviewers 
reviewed information about gatekeepers verbally, and discussed themes as they emerged. Notes were made that documented these discussions afterward. After it was decided to record and transcribe the remaining gatekeeper interviews, fewer notes were taken during the interviews, and these tended to be short notes that highlighted potential themes. Notes about interviewer discussions continued to be compiled after the interviews. In keeping with the constant comparative method, notes were reviewed regularly, and new data were reviewed and compared with previous data to determine commonalities and differences. Phenomena and concepts related to those phenomena were identified using an open coding process wherein the two authors made and compared codes and notes regularly, discussing perceptions and interpretations of the interview data. The themes identified in this paper emerged based on codes that came from interview notes, interview discussion notes, and the researchers' own reflections on the interview transcripts, and came after lengthy discussion between the authors as to the relevance of a particular code.

\section{Interviewee Information}

A total of ten gatekeepers took part in the interviews, and demographic information on gatekeepers was compared with other sources that focused on gatekeepers (e.g., Agada, 1999; Metoyer-Duran, 1993). The ten gatekeepers included a professor of Latin American history who had done considerable fieldwork herself, a Mexican store owner in a rural town, a university extension employee who worked with Latin American immigrants in a small town, a school social worker in a small town, a housing authority employee in a small town, a social worker at a Latin American heritage community service center in a larger Midwestern city, and two university health information professionals who were employed in a larger Midwestern city, one to write grants and do research, and one as a health outreach provider and interpreter. Two gatekeepers were informal gatekeepers, not affiliated with a specific agency or workplace but still very active in connecting their communities and therefore known to the Cambio Center. More information about the gatekeepers and the size of the communities in which they work is provided in Appendix A.

Each of the gatekeepers was English-Spanish bilingual and bicultural, although not all of them shared a cultural heritage with their populations. The Latin American heritage populations in the Midwest are mostly of Mexican extraction, with lesser pockets of Central American immigrants. The biculturality of the gatekeepers was generally manifest in the way they combined their country of origin heritage and their work in the host culture. All of them identified as having heritage from Latin American countries, and all worked in a predominantly white and Englishmonolingual culture in the Midwest. They all also shared the challenge of being strangers in a strange land after having moved to the Midwest. For example, one of the gatekeepers was from the U.S. territory of Puerto Rico, and moved to her town because it was the place where her father was last stationed when he was in the armed forces. Another immigrated to the U.S. after having been an exchange student in a rural Midwestern town. He chose to settle in a rural area in that state after college.

Although the gatekeepers were bilingual, their service populations were not necessarily entirely bilingual or even monolingual Spanish speakers. Some people they worked with spoke indigenous languages; many were very comfortable conversing in English as well. Some gatekeepers used different dialects of Spanish than those used by their target populations and were aware of the need to modify their language when working with immigrants.

Most gatekeepers were deeply involved in community affairs, positively engaged, and highly social. One had actively campaigned on behalf of a friend who was running for the city council. Another hosted community events to build connections among the Latin American immigrants in

The International Journal of Information, Diversity, \& Inclusion, 2(1-2), 2018

ISSN 2574-3430, publish.lib.umd.edu/IJIDI/ 
the community. Another, in her professional role, hosted television and radio call-in shows, and participated in a local college's lock-in overnight camp for young women of Latin American heritage. Yet another took volunteers to a rural area in a Central American country every year to help the people in that area build infrastructure.

Similarly to Agada (1999), the authors of this study found that most gatekeepers had a high level of education (i.e., had completed college degrees), were community residents (a criterion for Agada), and were employed. Many of the gatekeepers were actually employed in their roles as gatekeepers or community liaisons, which could ostensibly limit their role in information sharing to those things that were allowable and acceptable by their employers. Agada (1999) found that community-based gatekeepers who sought information from social service agencies preferred to deal with "'insiders' in the agency" (p. 82) who might understand their requests better. In this sense, some interviewees in this study might be seen as those social service agency insiders.

\section{Results}

Our interviewees differed in their approaches to engagement and community interaction.

University extension personnel were highly focused on delivering information and education to their target communities. They had a tendency to draw the linguistically diverse immigrant populations together for combined activities but did not necessarily try to integrate the population into the host culture. One exception to this was the programs that emphasized financial knowledge or entrepreneurship. University extension personnel who engaged in these programs did connect immigrants with bankers and chambers of commerce. Social workers, on the other hand, tended to function as gatekeepers or nodes, connecting individuals or families within the linguistically diverse populations with services or personnel outside of their networks. Information or resources were generally provided on an as-needed basis. In the cases of both extension and social work, services were provided by someone who was bilingual and bicultural.

The community connectors tended to function as social and cultural community glue. They provided cultural support, such as telling traditional stories and holding traditional festivities, to help bring together members of the immigrant community. They provided relatively little survival-type information but they did strive for a sense of community and self-recognition, which was well-received by people with whom they worked. And although the receiving communities (e.g., long-term white resident families) were generally not sought out for these kinds of events, they were not excluded either.

Agada (1999) points to research which suggests that the "context ... might be a better predictor of needs and uses of information than socioeconomic status" (p. 75). This fits with the finding that gatekeepers often end up creating a context for their services that encourages Latin American immigrant families to join them. For instance, one gatekeeper, tasked with spreading the message of tobacco prevention, created a program that addressed her community's wider needs and incorporated tobacco prevention among other topics. Another gatekeeper developed an aspirational vision of college and/or career readiness for her school-aged population to achieve, and geared her programming and interventions toward that aspiration, helping to take care of existing challenges so her students could improve. A third gatekeeper created a social network among his community that gave participants another reason for attending programs and events-socializing with each other. These examples demonstrate that being a gatekeeper is not limited to communicating information, it also means maximizing the social capital and social networks for creating a community with a shared context, goals, and aspirations. 
Below, the findings from the analysis of the interviews with the gatekeepers are presented according to the three primary themes that emerged: language, cultural relevance/applicability, and trust.

\section{Language}

As anticipated, language was a primary concern of our gatekeepers. The school social worker was acutely aware of stereotypes and perceptions about some families, but also aware that without information in a language they could understand, those parents were powerless to help their children navigate the American school system.

When I started with the interpreting and translation this year, a lot of the schools say that the families are not involved, and that the Hispanic families don't care. How do you know? Have you ever asked them? Have you ever given them the information? We need to make our schools more welcoming; we need to give them the same information, and once we have done that, then they get to choose if they want to be involved or not. But right now, they are not even giving them that choice. (School Social Worker)

This is not just a debate over Spanish versus English. This school in a small Midwestern town actually had 31 languages used by children in its service population but had only three people who could translate-one for Spanish, one for Russian, and one for Ukrainian. They have several churches that offered Spanish-language services but nothing for people with other language needs.

For Latin American immigrants who speak Spanish, finding resources in Spanish was essential. One health information provider discovered that the best means of communicating with her population was in Spanish over the radio.

We discovered radio is the way our community get information. When you think about a radio show like that, you have to think about people getting connected, getting that bonding, looking for people who sound like them. (Health Information Provider)

She mentioned that her population was "looking for people who sound[ed] like them," who were native Spanish speakers. In this instance, the provider was Puerto Rican and the population was mostly Mexican, but the fluency and the ease of language use were vital to their ability to communicate with her without linguistic barriers or feelings of discomfort that would come from working with someone who was only partially fluent in the language.

\section{Cultural Relevance/Applicability}

Newly arrived immigrants need more than just a translation of a document-they need to be able to incorporate the knowledge contained in that document into their world view and cultural understanding. This was powerfully illustrated by one of our respondents, who told a story about a cultural misunderstanding based on materials being translated but not being explained.

We had a Valentine's Day party for the school and we sent home a flyer that said: We have a Valentine's Day party for the school, bring 30 valentine cards, send something to decorate their valentine boxes. So the principal hands this to the translator. They take it, and it goes home. First time comers to the US read this. You know what the family did? With the paper in Spanish, they went to Walmart, they bought 23 Hallmark Valentine cards, not the little Valentine box that's $\$ 1$ for 30 of them. No, they bought $\$ 2$ valentine cards for each student and they bought a box and a gift paper and bows because they understood that there was going to be some wrapping. And it was to decorate a little 
shoe box that the teacher had in the classroom. So, we can't just translate things. It's the cultural competency part. Both from this culture to theirs, and from their culture to here. I always say, what's common sense in one culture is not common practice in the other. That's it. What I practice and what I feel is [a] norm for me is not for the other. (School Social Worker)

This pointed out the strong need for gatekeepers to understand cultural nuances, as well as the language, and to envision what a newcomer to their community might or might not understand about American customs and norms. Ideally, gatekeepers should be able to work with translators who might not be sensitive to these cultural differences.

Another thing that gatekeepers do is work to make sure they are meeting the real needs of the community, and not just the needs that outsiders perceive the community has. For instance, the health information provider mentioned that tobacco prevention was a strong priority for outside grant funders, but the standard tobacco prevention measures did not resonate with her community.

They don't care if you come knocking on their door to talk to them about tobacco. They're dealing with domestic violence, alcoholism, and mental health. But when you put those other aspects together, then they get involved. (Health Information Provider)

When she changed the program to be more responsive to community needs, she got more acceptance within the community.

\section{Trust}

Other ways for successful relationship building used by gatekeepers are continuity and presence. Gatekeepers make a long-term commitment to the community and are embedded within the community. This also means they are invested in the community's growth and success.

You need to build a relationship with people. They know me because l've lived here for a long time. They know my kids. I went to school here. (University Extension Worker)

This kind of long-term commitment and continuity is evidenced by the university extension worker quoted here, who was a fixture in his community along with his wife and children.

\section{Immigration to the Midwest}

Confirming some assumptions and anecdotal evidence about the choice to move to the Midwest, one of our respondents supplied the following information:

[My family] mainly wanted to get away from all the gangs and all that environment that you typically see in Los Angeles. So my uncle is a pastor here, he was offered to be a pastor at the first Hispanic church. Eventually my mom and my uncle got to talking and he said that we should come live over here. They have good jobs, the Tyson factory. You see a lot of Latinos working in factories. So then they decided to come this way to get away from all that stuff. And we already had a family member here so it made it that much easier. (Housing Authority Employee)

Integration is not, however, seamless for Latin American immigrants to the Midwest.

I came to [a particular city in] lowa in 1999 and what I found is that people were very, I would say, shy or embarrassed or programmed to think less of themselves as 
indigenous peoples, because [they] remember centuries of dehumanization of indigenous peoples, where our spirituality was considered belonging to the devil or our language doesn't amount to being a language, it's called a dialect, us being less than human, centuries of impositions of that way of thinking by powerful institutions including the state, including Christianity itself, not just one branch of it, but this entire idea that outside of this person Jesus, you cannot be saved. It's a very, very powerful way of destroying who you are, so from there, you don't really want to be called Maya. And what you try to do is become just like someone else. Being Hispanic, being Latino is the only thing that you are because anything south of the United States is called Latin America. (Community Connector)

This particular individual did a great deal of work connecting Mexican and Latin American residents from indigenous populations like the Maya. In our interview with him, he focused on feelings of isolation, misunderstanding, and misidentification.

\section{Engagement Challenges}

Finally, one concern that emerged was the ability to engage Latin American immigrant newcomers. Even the gatekeepers paid to engage with newcomers reported that it was not always easy to get them to participate. Although the gatekeepers had many advantages-they were bilingual, bicultural, and able to build a community-there were some community members who either did not want to participate or did not want to participate consistently. Some people would participate in one-on-one activities but not in group activities.

It's really hard to reach some people-a challenge, you know? And some people just don't want to participate. (University Extension Worker)

This serves as a useful reminder that within immigrant communities, and within the same ethnic or cultural populations, individual goals, needs, and preferences may greatly differ and play a powerful role in determining behaviors.

\section{Discussion}

As described, three interrelated themes emerged from the interviews: language, cultural relevance/applicability, and trust. Additional requirements for gatekeeping that emerged in the interviews were also presented.

In terms of language, interviewees focused on the need for their skills as translators. This supports the notion that, in the native tongue, "...education should, and can, be profoundly relevant and responsive to local community ways and concerns. ...the knowledge that the community uses and values on a daily basis" (Trudell, 2012, p. 372). Our gatekeepers played a dual role, first as translators of meaning, making sure that languages and terminology were appropriate for their users. These language-based services support language use and promote trust, enabling immigrant community members to participate in the activities of the host community and to navigate the culture more effectively.

A secondary "translator" role might be considered helping to facilitate the receipt and comprehension of messages especially emanating from members of the host community, as mediated by the mobile, social web. By serving as a kind of technical support for some members of the community, gatekeepers helped to ensure automated messages such as text messages were received and could be translated into Spanish using automated means like translator apps. In this way, gatekeepers may preemptively mediate communication difficulties. At this same time, they clarify that the translation quality will not always be good. In the case of 
parents with children in schools that communicate through the use of text messages and emails, gatekeepers will remind the parents that they have the right to seek more information when they need it.

While the term trust was not used explicitly, the theme of trust was clearly implicit in all interviews and became apparent in data analysis as the gatekeepers described their interactions with immigrants. The interviewed gatekeepers were active and respected community members, and were able to bridge the questions of language and applicability. Language skills are basic prerequisites for gatekeepers, and much of their work focuses on linguistic and potentially cultural differences. They are unable to work with immigrants and the broader community without appearing trustworthy and being part of the community for a respectable duration of time (which is referred to as continuity in this article). Additionally, their cultural competencies allow them to work with the newcomer community in a way that is relevant to its needs.

As part of developing relationships, the gatekeepers made friends with their immigrant community members and became involved with family events. They did not feel that their institutional roles precluded social relationships. Most gatekeepers were very social and sociable and looked forward to participating in group events, such as family parties and church picnics.

Because their roles as gatekeepers were more specifically oriented toward providing information for the benefit of their immigrant communities, they did not feel the need to present multiple viewpoints or multiple perspectives. Moreover, most gatekeepers were fairly traditional in their viewpoints on issues like drug use or health care. They shared specific information that was intended to improve the lives of their communities, as the gatekeepers defined it. In this respect, their charges differed from the charges of professional librarians seeking to provide unbiased information in accordance with established professional ethics. ${ }^{6}$

\section{Implications for Information Agencies}

\section{Implications for Larger, Well-Funded Information Agencies}

With adequate support, libraries can undertake the gatekeeper role in much the same way as our interviewees, keeping in mind that issues of language, cultural relevance/applicability, and trust apply equally in these situations. Librarians at larger institutions with funding and support might be able to function effectively as gatekeepers directly. Their work should echo that of the gatekeepers who were interviewed; that is to say, if librarians wish to engage immigrant communities directly, they should ensure that they are linguistically and culturally competent, sensitive, and trustworthy. They should be able to create a context and to support immigrants in coping with the problems considered relevant and urgent by immigrants themselves, not with the problems that members of larger society in general, and librarians in particular, deem important. The gatekeeping transaction is primarily unidirectional, with the flow of information from the host culture to the newcomer. Librarians should recognize the potential to use this relationship for two-way communication, so that underserved populations can be represented and better understood.

In the case of working with immigrant communities, gatekeepers who share a culture will be more skilled at communication (Edwards, 2013, pp. 508-9) and will likely be considered the ideal librarian intermediary. Hiring librarians or other staff members from the target culture, however, may not always be feasible. In the case where it is not, at least two solutions can be explored by libraries wishing to work directly with newcomer community members. First, recruiting and

The International Journal of Information, Diversity, \& Inclusion, 2(1-2), 2018

ISSN 2574-3430, publish.lib.umd.edu/IJIDI/ 
hiring staff with linguistic abilities and then supporting their LIS education is one option. Another option is to support language and cultural training for current staff. In both situations, the goal is to employ librarians or other information professionals who can connect to the community's members both linguistically and culturally.

Irrespective of their ethnic, linguistic, or cultural profile, librarians should in no way feel obliged to act in gatekeeping roles, considering that gatekeeping requirements will take them out of the scope of traditional librarianship. Librarians and other information professionals might feel uncomfortable if encouraged to engage with communities as individuals rather than in a professional capacity. Library staff who understand the functions and roles of gatekeepers and who are comfortable committing to them long-term will need to be identified. Those who choose to take on the gatekeeping roles and to support applicability and trust should be empowered to act for the good of the community. They should not be held to a script or policy that is detrimental to the community, such as sending patrons with $\$ 20$ of library fines to a collections agent without offering that patron an alternative way to make restitution for overdue fines. Librarians who take on these roles should also be prepared for a long-term time commitment, with varying degrees of effort expended throughout that period. Long-term commitments to services and programs will promote continuity and should be established as a point of departure for anyone wishing to undertake a gatekeeping role.

\section{Implications for Small Information Agencies}

Gatekeepers who are already working in the community should be considered a primary resource for librarians who reach out to newcomers as part of their library mission. In rural locations in particular, such as the small communities in the Midwest visited as part of this research project, there is little infrastructure to support librarians' work with immigrants. In the places with staff shortages (many of these libraries have only one or two professional librarians, a few paraprofessionals, and sometimes volunteers) and no accessible language classes for library staff, there is no reason for librarians to reinvent the wheel. The authors of this study, therefore, recommend librarians work with known and established gatekeepers. Additionally, librarians should rely heavily on input from gatekeepers in considering the needs of linguistically diverse immigrants and the best ways to meet those needs. This will inform their approach to collection development, services, and outreach activities.

By focusing on finding and building relationships with gatekeepers, libraries place themselves within the circle of trusted institutions which, in the long run, can be ready to support the immigrants in relevant and culturally sensitive ways. Gatekeepers can spread the word among their populations about the value of library use, and libraries can use gatekeepers in an advisory role to help them connect their programs and services to immigrant communities. Barzilai-Nahon (2008) and other authors note that gatekeeping, by its nature, is a relationship based on power and politics, which may influence what messages are shared. Consequently, libraries may have to use their political capital to get their message across.

In order to effectively address the needs of immigrant communities, libraries and other information institutions with limited resources should strive to partner with gatekeepers to provide services. Whereas larger libraries, typically found in large urban areas, might be able to engage in sponsoring health fairs and setting up sites for free clinics and tax help, smaller libraries can still make a meaningful impact on the quality of life of newcomers in their service areas with help from gatekeepers. By partnering strategically with gatekeepers who already know the language, understand their community's needs, and have gained the trust of community members, librarians can focus on the professional work that traditionally falls under their purview. 


\section{Conclusion}

The authors' work with gatekeepers in rural and low-population areas of the Midwest who serve Latin American immigrant populations is the first of its kind published in LIS literature. It builds off research from Metoyer-Duran (1993) and Chu (1999b), both of whom investigated ethnolinguistic gatekeepers in larger cities, and Agada (1999), who investigated African-American gatekeepers in another large city, Detroit.

This study's findings illuminate the work being done and align with prior gatekeeper research. Most notably, the findings indicate that gatekeepers play an important role in helping linguistically diverse groups to integrate into the new society and to meet their information needs. There are a number of roles that librarians and other information professionals can take on if they are interested in adopting a gatekeeper role in their communities. Unlike other researchers in the literature, however, the authors of this study expressly suggest that librarians in small communities with scarce resources should partner with established gatekeepers rather than attempt to function as gatekeepers.

\section{Endnotes}

1 The terms "Latino" and "Hispanic" are widely used in the United States to indicate people who have Latin American heritage, and/or whose ancestors emigrated from Latin American countries. The terms are acknowledged to be imprecise, as there is great diversity among Latin American countries. As this paper is directed toward an international audience, we generally use the term "Latin American immigrant," but the terms "Latino" and "Hispanic" may be used in quotations. In our original research, we used the terms "Latino" and "Hispanic," as these are the terms generally employed in the United States.

2 The term "Spanish-speaking" often refers to one particular trait of the Latin American immigrant community: their use of the Spanish language. However, there are Latin American immigrants who do not speak Spanish, such as those who come from indigenous communities. Spanish-speaking immigrants might also come from areas as diverse as Europe or even Africa.

${ }^{3}$ According to the website for the University of Missouri [MU] Extension (http://extension.missouri.edu/about/home.aspx), the University of Missouri, a public university located in a largely rural state of the Midwestern U.S. "is a land-grant university, meaning it is a part of a [U.S.] federally mandated mission to carry the benefits of university research beyond campus [... ]Today, through statewide offices, publications and Web-based services, extension faculty in every county of Missouri continue to carry the benefits of $M U$ research throughout the entire state" (n.d.). The Extension program, therefore, is the official vehicle for contact between the "land grant" public university and the people located throughout the state, including in remote, rural areas. There are five land grant universities in the states visited as part of this research project (https://nifa.usda.gov/land-grant-collegesand-universities-partner-website-directory).

${ }^{4}$ The 211 service is sponsored by the United Way and is available in the U.S. and parts of Canada. It is a free and confidential service connecting people with local health and human services professionals, with information about addiction prevention, services for veterans, support for domestic abuse, help for ex-offenders, etc. For more information about the 211 website: http://www.211.org/pages/about 
${ }^{5}$ For example, the Missouri Humanities Council has worked to establish the German Heritage Corridor. HB1851 was signed by the governor on July 1st, 2016 to designate 16 counties that hosted thousands of German newcomers as the corridor:

http: / /www.mohumanities.org/events/heritage-tourism/

${ }^{6}$ Further information about professional ethics and the American Library Association's code of ethics, including a link to the Code of Ethics document in English and in Spanish, can be found online: http://www.ala.org/tools/ethics

\section{References}

Adkins, D., \& Hempel, P. (2016, July 9). Information needs of the Midwestern Latino populations: A retrospective analysis of Cambio de Colores presentations. Paper presented at the Fifteenth Annual Cambio de Colores Conference, Columbia, MO.

Adkins, D., Moulaison Sandy, H., \& Derpic, J. (2017). Information sources of Latin American immigrants in the rural Midwest in the Trump era. Library Quarterly: Information, Community, Policy, 87(3), 243-256.

Agada, J. (1999). Inner-city gatekeepers: An exploratory survey of their information use environment. Journal of the American Society for Information Science, 50(1), 74-85.

Ayala, R., \& Ayala, M. S. (1994). Report card on public library services to the Latino community: Final report. Calexico, CA: REFORMA.

Barzilai-Nahon, K. (2008). Toward a theory of network gatekeeping: A framework for exploring information control. Journal of the American Society for Information Science \& Technology, 59(9), 1493-1512.

Berry, J. W., \& Hou, F. (2016). Immigrant acculturation and wellbeing in Canada. Canadian Psychology / Psychologie Canadienne, 57(4), 254-264.

Blanchard, S., \& Muller, C. (2015). Gatekeepers of the American dream: How teachers' perceptions shape the academic outcomes of immigrant and language-minority students. Social Science Research, 51, 262-275.

Bucerius, S. M. (2013). Becoming a "trusted outsider": Gender, ethnicity, and inequality in ethnographic research. Journal of Contemporary Ethnography, 42(6), 690-721.

Caidi, N., Allard, D., \& Quirke, L. (2010). Information practices of immigrants. Annual Review of Information Science and Technology, 44(1), 491-531.

Chu, C. M. (1999a). Immigrant children mediators (ICM): Bridging the literacy gap in immigrant communities. New Review of Children's Literature and Librarianship, 5(1), 85-94.

Chu, C. M. (1999b). Literacy practices of linguistic minorities: Sociolinguistic issues and implications for literary services. Library Quarterly 69(3), 339-359.

Cuesta, Y. J. (1990). From survival to sophistication: Hispanic needs = library needs. Library Journal, 115(9), 26-28. 
Edwards, R. (2013). Power and trust: An academic researcher's perspective on working with interpreters as gatekeepers. International Journal of Social Research Methodology, 16(6), 503-514.

Haro, R. P. (1970). How Mexican Americans view libraries. Wilson Library Bulletin, 44(7), 736742.

Jensen, L. (2006). New immigrant settlements in rural America: Problems, prospects, and policies. Reports on Rural America (Vol.1 No.3). University Park, PA: The Pennsylvania State University (A Carsey Institute Report on Rural America). Retrieved from https: //scholars.unh.edu/cgi/viewcontent.cgi?article=1016\&context=carsey

Jensen, L. A. (2008). Immigrants' cultural identities as sources of civic engagement. Applied Development Science, 12(2), 74-83.

Kandel, W., \& Newman, C. (2004, June 1). Rural Hispanics: Employment and residential trends. Amber Waves, 2(3), 38-45. Retrieved from https: / /www.ers.usda.gov/amberwaves/2004/june/rural-hispanics-employment-and-residential-trends/

Kim, E. (2016). Social service outreach programs using elderly Korean immigrants' church ties. Journal of Social Service Research, 42(1), 130-142.

Kogan, I. (2006). Labor markets and economic incorporation among recent immigrants in Europe. Social Forces, 85(2), 697-721.

Krogstad, J. M., \& Lopez, M. H. (2017, October 31). Use of Spanish declines among Latinos in major U.S. metros. Pew Research Center Fact Tank. Retrieved from http://www.pewresearch.org/fact-tank/2017/10/31/use-of-spanish-declines-amonglatinos-in-major-u-s-metros/

Krogstad, J. M., Stepler, R., \& Lopez, M. H. (2015, May 12). English proficiency on the rise among Latinos: U.S. born driving language changes. Pew Research Center: Hispanic Trends. Retrieved from http://www.pewhispanic.org/2015/05/12/english-proficiencyon-the-rise-among-latinos/\#spanish-language-use-among-u-s-hispanics

Latinos Surge in Midwest. (1996, July). Rural Migration News, 2(3). Retrieved from https: / / migration.ucdavis.edu/rmn/more.php?id=126

Lewin, K. (1947). Frontiers in group dynamics II: Channels of group life, social planning, and action research. Human Relations, 1(2), 143-153.

Lichter, D. T. (2012). Immigration and the new racial diversity in rural America. Rural Sociology, 77(1), 3-35.

Luevano-Molina, S. (2001). Mexican/Latino immigrants and the Santa Ana Public Library: An urban ethnography. In S. Luevano-Molina (Ed.), Immigrant Politics and the Public Library (pp. 43-63). Westport, CT: Greenwood Press.

Martinez, R. O. (2011). Latinos in the Midwest. East Lansing, MI: Michigan State University Press. 
Metoyer-Duran, C. (1991). Information-seeking behavior of gatekeepers in ethnolinguistic communities: Overview of a taxonomy. Library \& Information Science Research, 13, 319-346.

Metoyer-Duran, C. (1993). Cross-cultural research in ethnolinguistic communities: Methodological considerations. Public Libraries, 19, 18-25.

Pew Research Center Hispanic Trends. (2016). Estimated unauthorized immigrant population, by state, 2014 [Unauthorized immigrant totals]. Retrieved from http://www.pewhispanic.org/interactives/unauthorized-immigrants/

Rumbaut, R. G. (2004). Ages, life stages, and generational cohorts: Decomposing the immigrant first and second generations in the United States. The International Migration Review, 38(3), 1160-1205.

Shirazi, M., Shirazi, A., \& Bloom, J. (2015). Developing a culturally competent faith-based framework to promote breast cancer screening among Afghan immigrant women. Journal of Religion and Health, 54(1), 153-159.

Shiu-Thornton, S., Balabis, J., Senturia, K., Tamayo, A., \& Oberle, M. (2007). Disaster preparedness for limited English proficient communities: medical interpreters as cultural brokers and gatekeepers. Public Health Reports, 122(4), 466-471.

Stull, D. D., \& Broadway, M. J. (2013). Slaughterhouse blues: The meat and poultry industry in North America, 2nd ed. Belmont, CA: Wadsworth Cengage.

Trudell, B. (2012). Of gateways and gatekeepers: Language, education and mobility in francophone Africa. International Journal of Educational Development, 32(3), 368-375.

United States Census Bureau. (2011, May 26). 2010 Census shows nation's Hispanic population grew four times faster than total U.S. population. Retrieved from https://www.census.gov/newsroom/releases/archives/2010_census/cb11-cn146.html

University of Missouri Extension (n.d.). About MU Extension. Retrieved from http://extension.missouri.edu/about/home.aspx

White, D. M. (1950). The "gate keeper": A case study in the selection of news. Journalism Quarterly, 27(4), 383-390.

Denice Adkins (adkinsde@missouri.edu) is an associate professor at the School of Information Science \& Learning Technologies at the University of Missouri. She was a Fulbright Scholar to Honduras in 2008 and the President of REFORMA (The National Association to Promote Library \& Information Services to Latinos and the Spanish-Speaking) in 2012-13. She currently serves as Councilor-at-Large for the American Library Association and Secretary-Treasurer for the Association of Library and Information Science. Her research interests include information needs of Midwestern immigrants, library services to diverse audiences, and public libraries. She is a coinvestigator on the ALISE/OCLC grant funding this project.

Heather Moulaison Sandy (moulaisonhe@missouri.edu) is associate professor at the iSchool at the University of Missouri. Moulaison Sandy's primary research focus is the organization of information in the online environment, leading her to investigate areas related to the use of 
web-based and mobile technologies in libraries. An ardent Francophile and 2008-2009 Fulbright senior scholar in Morocco, Moulaison Sandy is also interested in international and intercultural aspects of access to information. She is a co-investigator on the ALISE/OCLC grant funding this project.

The International Journal of Information, Diversity, \& Inclusion, 2(1-2), 2018 